\title{
Influence of Speed Information Transfer on Safety of Society
}

\author{
Sergii Lysenko
}

\begin{abstract}
The article is sanctified to research of influence speed of information transfer on informative safety of society. An author extrapolates the outlined problem through the prism of laws of physics, what a conclusion allows to do about dependence of destructive energy of information on three indexes - volume, closeness and speed of distribution. In case of opposition of two (or more) opponents, possibility of informative threat is determined exactly by these parameters of the informative systems of each of them.

With development of informational technologies speed of distribution of information arrives at velocity of light, that increases importance of comparison of volume and closeness of information. A researcher insists on a necessity creation of such an administrative-legal paradigm that would provide the free and safe stream of information into society, at maintenance of rights and freedoms of man and citizen.
\end{abstract}

Keywords : informative safety, safety of society, information, speed of information transfer, volume of information, energy of influence.

\section{NTRODUCTION}

What farther we move in time, the anymore we suffer from informative dependence. Information already not to stop! Once she broke from the shackles of total censorship of Middle Ages, got boundless power and became a major asset in the world, for that, in our time wars begin even.

Information and her flows of data take consciousness of people even. A new religion based on the worship of information has already emerged - Dataism. She proclaims that Universe consists of flows of data and the value of any phenomenon is determined, foremost, by his contribution to processing of data. Dataism takes all more supporters. Religion combines biological and electronic algorithms, claiming that the same laws apply to deciphering them. The basic idea of Dataism is to further destroy the barriers between animals and machines, and the expectation that electronic algorithms will surpass biochemical methods.

The power of information cannot stop even a black hole in space. John Pericles, a professor at the California Institute of Technology and director of the Institute of Quantum Information, said that the radiation of a black hole carries the information that the hole absorbed earlier. The same idea was confirmed by the well-known black hole researcher Stephen Hawking, who in 2004 at the International Conference in Dublin stated that a black hole cannot destroy the information it absorbs. Together with the radiation of black hole, this information breaks forth, but only distorted by the gravitation

Revised Manuscript Received on November 10, 2019

* Correspondence Author

Sergii Lysenko, Dr. Law, Professor, Severodonetsk Institute of "Interregional Academy of Personnel Management" of hole. We cannot decipher her therefore [1]. Here into what opponent humanity ran in the XXI century, in the era of the conscious existence. In fact, except a value, information carries in it quite a bit threats.

\section{MATERIALS AND METHODS}

Introduction of methods the administrative and legal adjusting of informative safety becomes the main task of modern informative right. Without introduction of inter-branch algorithms control after the flows of informative data it is impossible keeping order and maintenance of basic rights. K. I. Belyakov [2], A. M. Podolyaka [3], S. G. Stetsenko [4], V. S. Tsimbalyuk [5] and a number of other authors wrote about this in their writings. Some aspects of the problem of the influence of the processes of transmission, dissemination of information on information security are already reflected in the studies of domestic authors. In particular, K. I. Belyakov notes the following about this: "at the stage of dissemination (dissemination) of information, certain information barriers take place, both technological and psychological, as a result of which information-legal conflicts arise ..."[2 ]. A. M. Podolyaka, analyzing becoming of informative society, marks other aspect of threats: "from one side, information of extraordinary extended cognitive and other possibilities of man, and with other, there is the problem related far not to positive influence of information on the psyche of man. Information, if she is not controlled by a man, is able radically to change psychological, socially-spiritual values and orientations of man. So, spiritual life of people can be exposed to large negative influences" [3]. At the same time, problem of influence of speed of information transfer on informative safety in particular and safety of society on the whole, did not yet find the reflection in scientific thought and requires further, careful researches.

The problem: to carry out the analysis of factors influencing on informative safety of organizations, as objects of defence and possible negative influence of information, in the context of height of speed of information transfer.

\section{RESULTS}

Considering nature of information, we consider a necessity, foremost, more detailed to look closely to influence of informative flows of data. Information must be studied in all her displays. It is special topically, when we talk about informative safety. Except already mentioned, we are convinced, that the study of this phenomenon will allow more successful to analyses informative influence, to informative safety and possible consequences from negative informative destruction. 
From the point of view of safety, negative influence or degree of damage disturbs us, foremost, one or another force (in this case is information and her streams) can inflict. Exactly by losses or destructive consequences, probably, the danger of influence is characterized. In the context of informative safety, we talk about losses and destructions that can cause informative streams and that it is necessary to be able to forecast and identify for the further warning and rendering harmless.

Like with the surrounding world, any destructive capacity or danger is characterized by destructive energy. Id est., than more energy of negative influence, the stronger destruction or losses will entail one or another negative information, the more powerful her destructive potential.

We understand that negative information carries negative energy, and positive, accordingly gives positive formative energy. However, while the question is exactly about the aspect of power, but not positive or negative colorings of the indicated energy. For the faithful understanding and analysis of the phenomenon of energy of influence, it is necessary to appeal to fundamental concept of energy. It is known from the laws of mechanics, that energy is a scalar physical size, being the single measure of different forms of motion of matter and measure of transition of motion of matter from one form in other. For description of different forms of motion of matter enter the concept of different types of energy, for example mechanical, electrostatic or quantum, depending on the type of matter or information. According to the law of conservation of energy, power or size of energy, remains unchanging, id est. negative influence from informative energy will remain unchanging, but energy can go across from one kind in other. So, first examined by us, mechanical energy is equal to the mass, increased on the square of speed, divided into two, and measured to the formula:

$E=\frac{m * V^{2}}{2}$

where "E" - is precisely energy; "M" - mass; «V" - speed [6]. Analyzing the indicated formula, it is possible to assert that energy of influence, id est., her potential destructive capacity, depends on two sizes. If to talk at informative influence, then she depends on mass of information and from the rate of her movement or distribution. In spite of the fact that in a formula measuring of speed erected in a square, it is possible to draw conclusion, that energy of influence much more depends on exactly speeds what from mass.

As possible to notice, for the beginning of analysis we took mechanical energy exactly. It contingently the row of reasons. All objects having certain energy and can influence on the surrounding world possess speed incomparably less velocity of light. And such sizes submit to the laws of mechanics. Information transfer, in old times took place by means of mechanical devices and human possibilities. A certain analysis of various possibilities for the transfer of information studied [7]. We have already considered how information was passed from face to face when people were carriers and guardians of information. With the creation of writing and the emergence of literary works, an accumulation of information took place, that is, it was possible to increase its mass in a certain place. But, all the same, the importance of information was expressed by the possibility of a quick transfer. was carried out by the author in a previous publication, where the genesis of information security in military affairs was

From the beginning, information was transmitted from face to face with the speed of movement of people in their habitat space. In the process of the development of civilization, the speed of movement began to depend on the speed of the horses. That is, the information began to be transmitted faster, couriers used horses and information communication between individuals became more effective. This made it possible to create strong social groups and more strongly influence the world around us. Due to the fact that the influence was not always positive, we can say that the speed of information transfer increased the danger of the influence of information on the social systems of people. That is, the destructive energy of the impact of information, really, mainly depended on the speed of information transfer.

In the above-mentioned article, the author pointed out what energy or destructive significance even insignificant information could have inflicted which was quickly delivered or transferred to the right place at the right time. Stories are known when a small team quickly delivered the fate of an entire war. That speaks about the fidelity of our assumption about the much greater importance (for the impact energy) of the speed of information than its mass [7].

Over time, information transfer technologies became more sophisticated; information began to be transmitted through transport and then radio and wired electromagnetic communications. In the XIX century, the speed of information transfer increased hundreds of times. It was then that the majestic offensive of information danger on humanity began. The time has come when people felt the full power of information, its destructive energy. Those times became the apogee for spies and scouts, and then the first professional attempts were born to create information security tools.

The twentieth century gave human civilization the Internet. And during this period, the speed of information transfer approached the speed of light. That is, "V" approached "C", and almost became equal to 300,000 kilometers per second. As it is known from the physics course, this is the maximum possible speed that can exist in our Universe (according to modern scientists) [2].

With such a tremendous amount of speed, the destructive power and energy of the impact of negative information on certain objects became colossal. This led to a revolution in military conflict management and influence strategies. Completely changed the scale of values. The objectives of military conflicts have shifted from the physical capture of certain territories or natural resources to the possibility of owning knowledge and controlling certain information flows. Knowledge and information have become the main subject of any conflict [8].

Although it can be noted that some countries, realizing the destructive power of information at such a speed of its transmission, deliberately slow down this speed in their large territories. Intentionally creating obstacles, or changing the transmitted information in their favor, realizing that the truth will not soon reach the user, or when it reaches, its value will decrease significantly. For example, the accuracy of the transmission from Moscow to Kamchatka, at a certain level of communications, will not soon be verified by users, which allows the leadership of the Russian Federation to manipulate its multi-million population. 
Achievement of information the maximum possible speed of its transmission, in a certain way equalized the capabilities of the conflicting parties. As it is known from the works of modern scientists, information security analysis or the degree of impact can be assessed by comparing one with another. This refers to a comparison of the capabilities of the information destructive energy of one participant in an event with a similar indicator of the opposite side. Any assessment is the process of comparing the object with the chosen one. The chosen object can be a standard, or opponents, between which it is necessary to determine the advantage [9].

For the analysis and assessment of hazards, we create our own methodology, which should be based on the use of physical laws. The use of certain formulas will allow us to move from non-specific prediction or game theory, provide only plausible conclusions or (at best) several possible options, in clear calculations with specific digital indicators.

So, we have determined that the potential information danger is characterized by the size of the negative impact, the size of the destruction and the size of the consequences. In the physical sense, this is all called the impact energy, has a certain formula, which depends on the mass of the object of impact and the speed of its movement. In the case of information, this is the speed of information transfer. So, comparing the energy of the impact of one opponent with the energy of the impact of another, we must determine the one who has more energy. Such an opponent is capable of inflicting greater danger, and the latter, respectively, will be forced to defend more strongly.

Maybe sometime in the future, opponents will not use violence during conflicts, but using our conclusions and formulas will calculate their capabilities and determine the winner. Thus, they will save their time and money.

In the form of formulas, we must compare $E_{1}$ with $E_{2}$.

As we saw above:

$$
E_{1}=\frac{m_{1} * V_{1}^{2}}{2}
$$

while,

$$
E_{2}=\frac{m_{2} * V_{2}^{2}}{2} \text {. }
$$

Id est., we must compare next expressions: $m_{1} * V_{1}^{2}$ and $m_{2} * V_{2}^{2}$.

If we are talking about old times, then this comparison is valid, and the use of these formulas is illustrative. Relatively speaking, "adversary 1" had a better-tuned signal transmission system and was able to transmit information twice or three times faster, took advantage of "adversary 2" (4 and 9 times respectively). But, in our time, the speed of information transfer is close to the speed of light; therefore, the calculation of the size of the impact energy will occur by the Einstein formula:

$E=m * C^{2}$

where, "C" - is velocity of light, "m" - is mass [6].

It follows from this that any speed of information transfer became maximal already and will be identical for all masses. Id est., a statement will be faithful: $V_{1}=V_{2}=\mathrm{C}$.

Now back to the analysis. The evaluation, which was carried out between $E_{1}$ and $E_{2}$, should now be carried out between the expressions: $\left(m_{1} * C\right)$ and $\left(m_{2} * C\right)$. We observe that among the compared quantities there are identical factors, namely, in these quantities the same speed " $\mathrm{C}$ ". This suggests that when comparing expressions that define energy, in which the speed

is the same, it no longer determines the winner of the comparison. Therefore, speed is not the determining factor when assessing the energy impact on information security. Now the decisive indicator for comparing the two energies of influence becomes mass. Therefore, it is safe to say that in the modern world, the mass of information already plays a decisive role on the energy of the impact of information security.

But how to determine the mass of information? It is impossible to physically consider what mechanism. Indeed, in the usual sense for us information has no mass. However, if we consider the physical formula of mass, we can make certain analogies and determine the value that meets the requirements of the energy formula and corresponds to the mass or was able to be compared.

From physical references, we know that mass is equal to the density of a substance multiplied by its volume:

$m=p * Q$

where, "m" - is mass, " $\quad p \quad$ - $\quad$ is a closeness, "Q" is a volume of substance [6].

So, we face the task of determining the density and volume for a substance such as information.

Let's start with the volume, because by its value it is responsible for a specific quantitative environment where a certain substance accumulates, and in our case - information. Density determines the density of a substance, and in our case, the importance of information and much more. Therefore, with the same volume of two substances (and in our case, two types of information), the destructive impact will be caused by the energy that emerges from the substance (information), has a greater density. We see that the definition of the density of information is complex and diverse. The question of determining the density for information, in the course of information security analysis, will be disclosed in our subsequent studies.

In the meantime, focus on determining the characteristics of the amount of information. This question seems to us quite simple, because programmers have already noted that information is transmitted in the form of a binary code (01), and its volume is measured in bits and bytes. This approach fully meets our requirements, since it allows the use of the appropriate units in physical formulas. We conclude that the amount of information "Q" is measured in units of storage and processing of digital information. In modern cybernetic systems, information is measured in bits and bytes; one byte consists of eight bits. Accordingly, the impact on the power of information energy on a particular object will directly depend on the size of the value of storing and processing digital information, and therefore on the amount of information. Our study is aimed at a thorough analysis of the factors affecting the information security of organizations, as objects of protection and the possible negative impact of information. Our analysis shows that the destructive impact can be determined by the impact energy. In turn, energy depends on the speed, volume and density of information. Based on the above, we can conclude that the administrative and legal provision of information security of organizations should focus on regulating the three main indicators of information: its speed, its volume and its density. 
By increasing, in an administrative way, with the help of an integrated approach, the speed of information exchange and transmission, information security entities will be able to strengthen and improve their information security organization. At the same time, the administrative and legal provision of information security is manifested by reflection in the relevant regulatory acts of organizations. In addition to this, we must think about the future. The globalization of society and the saturation of data flows create certain threats of uncontrollable changes in the world. States deny the free market information, the wisdom of the crowd and external algorithms because they cannot manage the flood, flood of information data. In the past, censorship served as a regulator of such flows. Nowadays censorship is trying to act by overflowing people with inappropriate information. They simply do not know what to look for and are distracted by learning irrelevant questions. Therefore, our goal is to create an administrative-legal paradigm that would ensure a free and secure flow of information within society. Our goal is to develop such algorithms that universally process all data and ensure the preservation of human dignity.

\section{CONCLUSIONS}

The destructive power or danger of information is characterized by destructive energy. The greater the negative impact energy, the greater the destruction or loss of one or another negative information, the more powerful its destructive potential. The energy of information is directly proportional to its volume, density and the square of the speed of its distribution. With the development of information transfer technologies, its transfer speed is close to the speed of light, which makes it necessary to compare, first of all, the other two components that determine the energy of information - its volume and density. Administrative and legal support of increasing the volume of exchange or accumulation of information, as well as its storage, possibly by following the instructions and functional responsibilities of members of organizations. The administrative regime of this activity reflects cross-sectoral approach to ensuring the information security of organizations. Thus, the increase in the volume of operational information of the organization will positively affect the strengthening of its information security. And vice versa, if it is necessary to destroy the effectiveness of an organization's information security, then the above-mentioned factors should be influenced. The speed of information may decrease due to the destruction of communications, networks and communications. The amount of information depends on the method of storage and storage, as well as on the number of users, each of whom operates with a certain amount of information. That is, if users, storages or storage media are damaged, its volume will be reduced, and therefore the organization's security will be destroyed. Characteristics of the same information density will be disclosed in the next publication.

Our goal now is to create an administrative-legal paradigm that would ensure a free and secure flow of information within society. This requires the development of such algorithms that universally process all the data, and at the same time ensure the preservation of the rights and freedoms of man and citizen. The proposed approach to the analysis of ensuring the security of information data is effective with the most modern means of information security. And it is the main component for the subsequent creation of a general security theory of everything, which should fulfill the role of the paradigm that is planned to be created on the basis of the built-in special theory of information security.

\section{REFERENCES}

1. Soft Hair of Dynamical Black Hole and Hawking Radiation. Mirror of the week January 19, 2016.

2. Belyakov K. I. (2013). Offense in the information sector of national security as an extreme form of conflict situation. Fight against organized crime and corruption (theory and practice), Vol. 1. - P. 313-323.

3. Podoliaka A. M. (2013). The Phenomenon of the Information Society in the Context of the Civilizational Development of Mankind. Scientific Works of IAPM (EUCEN). - Vol. 4. - P. 5-8.

4. Stetsenko S. G. (2007). Administrative Law of Ukraine Textbook - K. Atika.

5. Tsimbalyuk V.S. (2015). Scientifically-doctrinal provisions on methodological installations of systematization of legislation on information. Information and law. Vol. 2. - P.76-83.

6. Yavorsky B. M., Seleznev Yu. A. (1989). Handbook of physics for entering universities and for self-education, 4th edition, - M. Science.

7. Lysenko S. A. (2019). Principles of Information Security in the Works of Classics of Military Thought (Part One). Public Law, Vol. 1.

8. Harari Yu.N. (2018). The Divine Man, behind the scenes of the future. Kiev. Book Chef.

9. Lysenko S.A. (2017). Theory of administrative and legal regulation of information security of enterprises: monograph. Kiev House "Personnel".

10. Lysenko S. O. (2019). Modern trends of informational security development, as a literary objective. Public management - 2019. - № Vol. (17) - P. 200-229.

11. 11. Tsekhmister,Ya. (2008). Mesoscale Confined Liquids near Criticality: Diffusion and Thermodiffusion Properties.. 22nd General Conference of the Condensed Matter Division of the European Physical Society, Rome (Italy); 01/2008

12. Tsekhmister, Ya., Gandzha, I., Chernenko, L., Lukomsky, V., Chalyi. A. (2003).Singular fourier approximations for calculating potentia water waves on infinite depts. The 5 Th Euromech fluid mechanics conference, Toulouse, France; 01/2003

13. Tsekhmister,Ya.,Chalyi, A. (1997). Hopf and Turing bifurcation in fluctuatinal models of self -organization. Condensed Matter Physics $01 / 1997$

14. Tsekhmister, Ya., Gandzha,I., Chernenko,L., Lukomsky, V. (2003). Comparison of ordinary and singular fourier approximations for steep gravity and gravity-capillary waves on deep water. The 28th General Assembly of the European Geophysical Society, Nice, France; 04/2003

15. Tsekhmister,Ya. (2003). Computational analysis of periodic gravity waves on a free water surface in the vicinity of limiting steepness. Conference computational physics. Bulletin of the American physical Society., San Diego, California, USA; 01/2003

16. Chalyi,A. V., Tsekhmister,Ya. V., Chalyy,K. A. (2010).Teaching and Learning of Medical Physics and Biomedical Engineering in Ukrainian Medical Universities. World Congress on Medical Physics and Biomedical Engineering, September 7 -12, 2009, Munich, Germany, 01/2010: pages 383-384; DOI:10.1007/978-3-642-03893-8_110

\section{AUTHORS PROFILE}

Sergii Lysenko, Dr. Law, Professor, Severodonetsk Institute of "Interregional Academy of Personnel Management" 